\title{
Incorporating ABET “Soft Skills” into Energy Conversion Courses
}

\author{
Timothy L. Skvarenina \\ School of Technology, Purdue University
}

\begin{abstract}
Both the Engineering Accreditation Commission (EAC) and the Technology Accreditation Commission (TAC) of ABET have adopted outcome-based evaluation criteria. The EAC began the process with early visits in 1997. TAC began later with the adoption of its Technology Criteria 2000, or TC2K, and conducted its pilot visits in 2001, with full implementation in 2004. In both cases, there is a list of required student outcomes, the so-called "a' through " $k$ " lists. Although they are different for the two commissions, there are many similarities, particularly in what are commonly referred to as the "soft skills." These include teamwork, communications skills, global perspectives, ethics, life-long learning, and contemporary issues. Often the faculty would like to leave many of these to the students' humanities and social science courses. However, at many schools there is a wide variety of electives for students in those areas and it is impossible to guarantee that they will receive exposure to all of the a to k items. Thus, it is the author's contention that the technical courses must cover these topics.

The author teaches a required course in Electrical Power and Controls in the second year of an Electrical Engineering Technology program. To insure that students are exposed to ethics and global perspectives, two case studies were developed relating to these areas but also to the course topics. Specifically one case study addresses the Enron Corporation debacle while the other addresses global warming and the Kyoto Protocol.
\end{abstract}

This paper describes the case studies, how they were used in class, and some of the results of student discussions.

Introduction

The Engineering Accreditation Commission (EAC) and the Technology Accreditation Commission (TAC) of ABET have both moved to outcomes-based accreditation of engineering and technology programs, via EC 2000 and TC2K, respectively. Both EC 2000 and TC2K require that every accredited program develop a set of program outcomes, which must insure that students have demonstrated the achievement of eleven outcomes, the so-called "a" to " $k$ " lists. The outcomes are different for the two sets of criteria, but they have a number of similarities. Table 1 shows a listing of the "a" to " $\mathrm{k}$ " outcomes for EC 2000 and TC2K. With the change from previous accreditation criteria, ABET has gone away from the so-called "bean counting" that required certain numbers of credit hours in various categories, such as mathematics, sciences, social sciences, and humanities. Instead each program must evaluate and assess its curriculum on a continuous basis to show that graduates are demonstrating the required outcomes.

"Proceedings of the 2004 American Society for Engineering Education Annual Conference \& Exposition Copyright 2004, American Society for Engineering Education” 


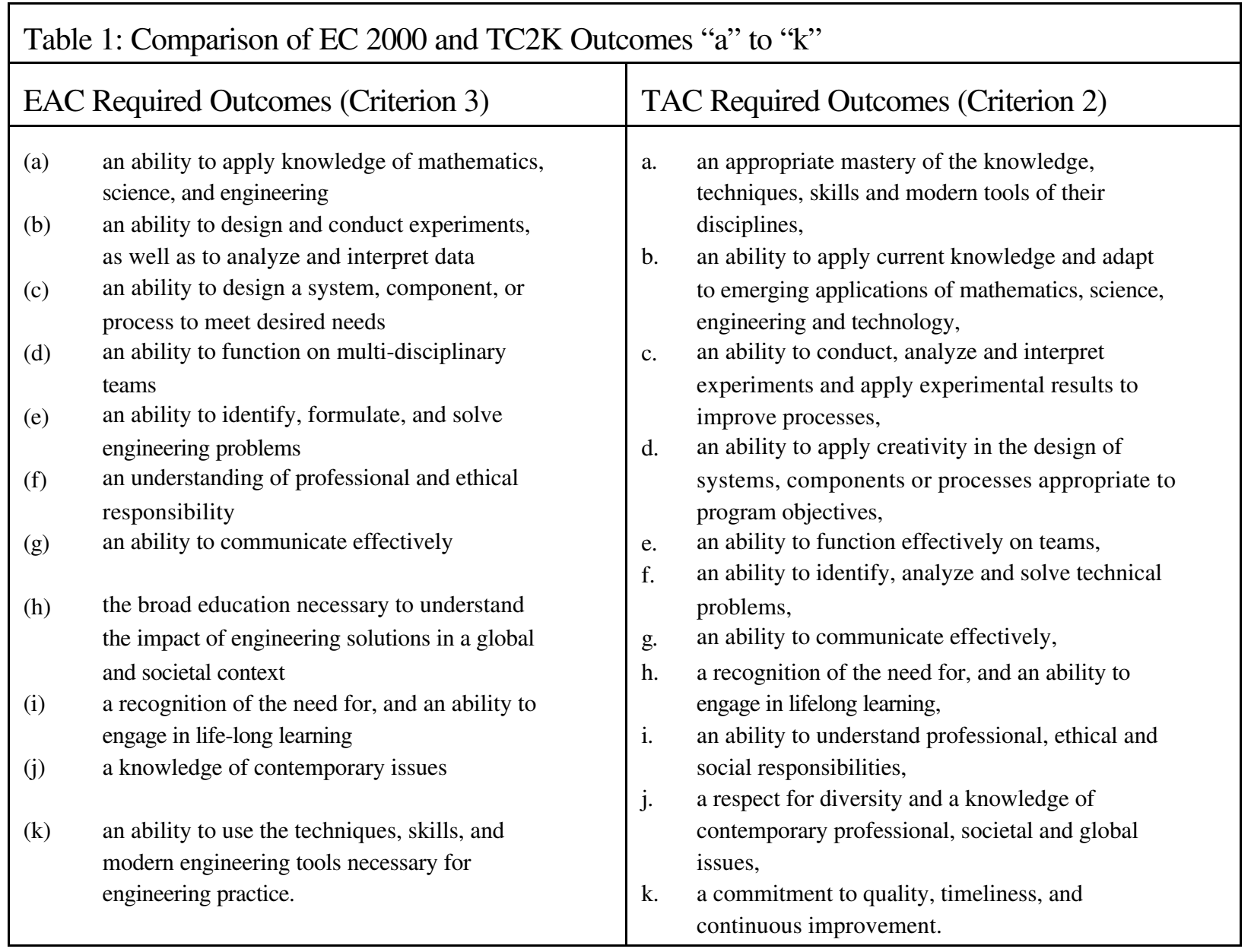

Looking at the ABET required outcomes, it is clear that a number of them not technical and they are sometimes referred to as "soft skills." Among these soft skills are ethics (EC 2000 outcome " $\mathrm{f}$ " and TC2K outcome "i $i$ ”), teamwork (“d”" and "e"), global perspectives ("h" and “j”), diversity (“j” in both), communications ("g" in both), and life-long learning ("i" and " $h$ "). These skills are, in many cases, learned by the students in their non-engineering and technology courses; however, it is the responsibility of the engineering and technology faculty to assess and evaluate the student learning in those areas. At large schools, such as Purdue, there are a vast number of courses that students may take to fill their humanities and social science electives. One alternative would be to require certain courses that cover the desired materials, but that defeats some of the advantages of attending a large school, specifically the ability to tailor a program to one's interests. In addition, there is the problem of getting classroom assessment from faculty who are not in the engineering or technology department that is being accredited. In view of these problems, I believe that the technical courses in the curriculum should contribute to the teaching and assessment of the soft-skills. In particular, some of these topics can be taught using material that is germane to the technical course.

I teach a course titled, "Electrical Power and Controls," in the Electrical Engineering Technology Program at Purdue. It is a fourth-semester course and is required for all students in the program. This 
course has been described previously ${ }^{1}$, but it includes topics such as single and three-phase power, power quality, basic magnetics, transformers, induction motors, relay controls, motor protection and feeders, and programmable logic controllers. In looking to find a way to contribute to the department's assessment process I wanted to find something related to the course topics. The first area that came to mind was ethics, because unfortunately one didn't have to look very far to find ethical misconduct in the electric power business. Although it was largely brought on by a poorly designed deregulation process, the California Energy crisis was certainly exacerbated by the actions of some of the energy providers. Of course one name that came up frequently in articles discussing the California crisis was Enron, which later collapsed as a result of severe ethical shortcomings and financial chicanery, costing investors some $\$ 100$ billion. So I concluded that ethics was an area that could be discussed in the context of the energy business.

A second area that came to mind was that of global perspectives. People usually think of their electrical utility as a local company with operations confined to perhaps a portion of their state. However, with deregulation and globalization, many utilities have split into regulated and non-regulated subsidiaries of a common company that is active in the international markets. This lead me to believe that something could be done in this area as well. Since global warming has been in the news quite a bit during the past few years and is largely blamed on electrical generation, it seemed like a good topic to use as the basis for a discussion of the international implications of technology and the global economy.

Having chosen two soft-skills to emphasize in the course, I was faced with the question of how to include them. I decided that although both topics (Enron and global warming) were extensively reported in newspapers and magazines, it was unlikely that my students (most of whom are 20-21 years old) would have any detailed knowledge of the specifics. To provide background information for the students, I developed two case studies that could form the basis for class discussion of the issues. Appendix A to this paper contains the Global Warming case study and Appendix B contains the Enron case study. One 50-minute class period was devoted to each topic, which meant that something had to be taken out. Time was made available by deleting the first lecture of the course which was a review of basic mechanics concepts (energy, force, work, etc.) and by deleting a single lecture on power system grounding. In the remainder of the paper, I will describe how the case studies were used in class.

\section{Ethics Case Study}

The class began with a discussion of what ethics is. Two dictionary definitions were provided:

\section{The study of the general nature of morals and the specific moral choices an individual makes in relating to others}

\section{The rules or standards of conduct governing the members of a profession.}

The second definition lead into a discussion of the IEEE Code of Ethics. I provided the students with some background, such as the first AIEE Code of Ethics was published in 1906, that the IEEE has had one since it was formed in 1963, and that the latest revision was in 1990. As we went through the

\footnotetext{
"Proceedings of the 2004 American Society for Engineering Education Annual Conference \& Exposition Copyright 2004, American Society for Engineering Education”
} 
statements in the IEEE Code, we discussed how they were apparently violated by employees of Enron and how that lead to the financial disaster that Enron became.

I also provided them with copies of the NSPE Engineers' Creed as another example of a Code of Ethics and the class discussed how those provisions were violated as well. Something that surprised the students was that Enron did in fact have a code of ethics as well. Some of the highlights of it were as follows:

! Issued July 2000, 64 pages

! Nothing detrimental to company allowed

! No separate financial gain for employee

! Truthful advertising and promotion

! No favors given for bribes, kick backs, gifts

! No libel or slander about company, people

! Honest relations with customers, public

We discussed some of the reasons people might not report ethics violations and of course fear of retribution was the top reason cited. In fairness to the students, I gave them some figures concerning what happened to whistleblowers in $1991 .^{2}$

! $90 \%$ lost jobs or were demoted

! $26 \%$ sought psychiatric or medical care

! $15 \%$ divorced after the incident

! $10 \%$ attempted suicide

! $8 \%$ went bankrupt

Despite these figures, reporting of misconduct by employees has increased steadily in surveys conducted in 1994 (48\%), $2000(57 \%)$ and $2003(65 \%){ }^{3}$

Finally to bring home to the students that unethical behavior is everyone we did a little exercise. Each student was given an index card. On the card, I asked them to answer the following questions:

1. Do you think you would report ethical violations at a company where you were employed?

2. Have you ever downloaded music without buying the CD?

3. Have you ever downloaded a movie?

4. Cheated on an exam or quiz?

5. Would you report someone you knew was cheating?

The questions were not provided all at once, however. After the first question, I asked the students to trade cards with someone and then to immediately trade with someone else. I then revealed questions 2, 3, and 4 and asked them to answer those on the card they had. The cards were shuffled again and the last question was asked. After a third shuffling of the cards, I asked those who had a yes answer on 
the card they were holding to stand up as I went through the questions. This way the students were not reporting their own answers. The results were quite revealing. Of 54 students in the class:

! 42 said they would report ethical misconduct where they were employed

! 52 admitted to downloading music and not buying the CD

! 40 admitted to downloading movies

! 29 admitted to cheating on an exam or quiz

! 19 said they would report someone they knew was cheating on an exam

The class was concluded with a short "quiz." I asked each student to reflect and write down the two more important things they learned from the discussion in class. A number of students were surprised at how wide spread the misconduct was at Enron. Several noted that it involved financial people and engineers; one student perceptibly noted, "It takes a lot of people looking the other way for something like the Enron scandal to occur." Several indicated that they really hadn't considered small decisions, such as downloading music, from an ethical standpoint before or that it is easy to break a code of ethics if excuses are made.

Finally, near the end of the semester, I gave a survey to get the students' opinion of whether the outcomes of the course had been accomplished. Answers were on a scale of 1 to 5 with 1 indicating strongly disagree and 5 indicating strongly agree. The response to the question, "The material covered in the ethics case study discussion helped me to understand the ethical responsibilities of a career in engineering technology," yielded an average score of 4.06, indicating the students did believe the class discussion was useful.

\section{Global Perspectives}

The global perspectives discussion was done during the $10^{\text {th }}$ week of the semester, after many of the major course topics had been covered. Figure 1 shows a picture of a well-known car. I used this to start the discussion of global perspectives. I asked the students several questions. Everyone could tell me that the car is a PT Cruiser. Many could tell me it was a Chrysler when I asked the company that builds the car, but less than half the class could tell me the company was Daimler-Chrysler and that the company is headquartered in Germany. Finally, most students assumed the car was built in Detroit, a couple guessed Canada. Only one student correctly identified Mexico as the location where it is built. I pointed out to the students that here was a car primarily designed for the United States market that was produced in Mexico by a company headquartered in Germany. Clearly, this car is an example of the world economy at work.

For a second example, I moved to the electronics arena, since EET students are very familiar with electronic devices. Figure 2 shows a picture of two MOSFETs that were removed from a dead UPS unit. I asked the students where they were made and virtually all of them identified Morocco as the country of origin. I told them they were a bit more enlightened than the average person. I had entered the part number of the MOSFETs into Google to find the ratings of the devices and the first entry that came up was an electronics Q\&A site. Someone had asked where they could get a data sheet or 


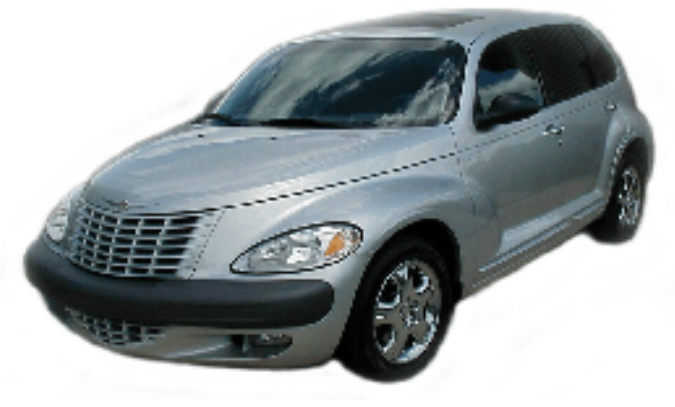

Figure 1: Attention getter for global perspectives discussion

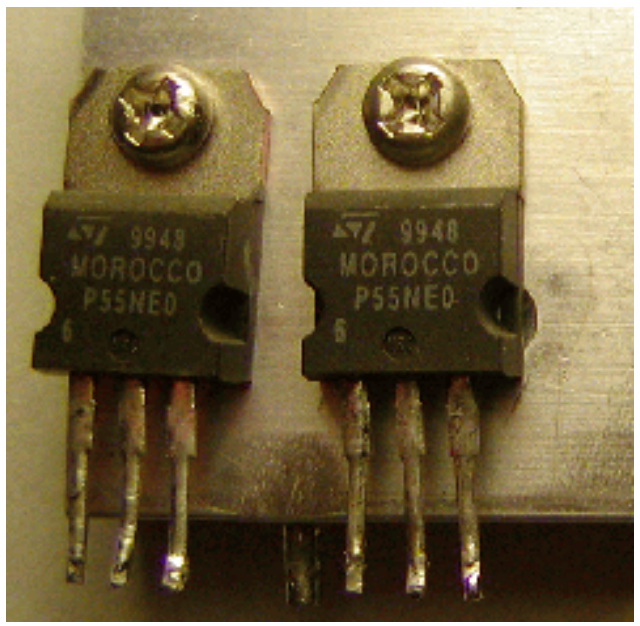

Figure 2: MOSFETs for discussion of global economy

replacement part for the P55NE transistor by Morocco. My students found that amusing, but I pointed out to them that the average person doesn't realize how global the electronics business is.

As an example of international standards and their effect on our ways of doing business, I showed the students a short report ${ }^{4}$ from Business Week Magazine that indicated the European Union plans to require lead-free solder in all electronic equipment by 2006. The students immediately realized that if Europe did that, then we would have to do the same if we wanted to sell any products there. I then showed them web pages for AEP, Cinergy, and AES, which operate electric utilities in Indiana. To the students surprise, all three "local" utilities describe international operations on their web pages. As one final example of the effect the world economy could have on their future, I showed the students a report $^{5}$ that the average electrical engineer with five years experience makes $\$ 106,000$ in San Jose, CA; about \$38,000 in Hong Kong; \$12,000 in Shanghai; \$10,000 in Mexico City; and about \$7,000 in Bombay.

Following these relatively brief introductions (10-15 minutes), the bulk of the class was spent discussing the global warming case study and answers to the discussion questions. As with the ethics case, I required students to bring their typed answers to class for the discussion. The discussion provided an opportunity to discuss alternative energy sources, especially wind power. Students were surprised to learn that significant amounts of wind powered generators are being installed in the U.S. Figure 3 shows the planned and actual installation of wind power in Texas, with some $1900 \mathrm{MW}$ added in the first two years of a eight-year plan.

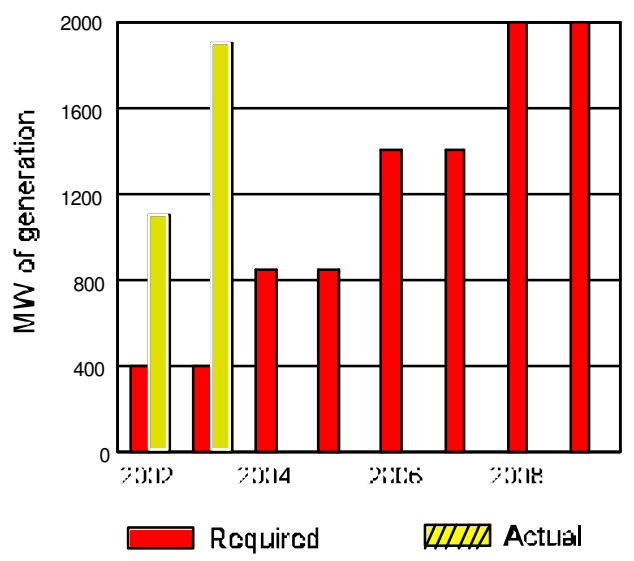

Other topics discussed included carbon sequestration, a

Figure 3: Texas Wind Generation 
process in which hydrogen is removed from the fuel and the carbon dioxide is buried at great depths below the surface of the earth. I pointed out to the students that technology such as this is one way the U.S. can help to solve problems and that they will probably see such things during their careers. A final topic that I showed them concerned the delivery trucks used by UPS and FedEx. Both companies are planning to use low-emission vehicles in their fleets in the future both to reduce operating costs as well as to contribute to cleaning up the environment.

The class concluded with a "quiz" that consisted of two questions: 1 . What was the most important thing you learned today, and 2. What effect do you think the world economy will have on your career. In response to question 1, many students indicated they weren't aware of the problem with $\mathrm{CO}_{2}$ emissions before, a number indicated they learned that we could do things to help reduce emissions, and some said they learned that standards from other companies could change the way they would have to design products. In response to question 2, some students expressed fear that they would have a harder time staying employed or making as much money as they wanted due to the global economy, while others embraced it as an opportunity to work with people from other countries. A few students said they were taking foreign language minors or doing study abroad programs to help prepare for a career in the global marketplace.

In the end-of-semester survey, students were asked their level of agreement with the statement, "The material covered in the Kyoto Protocol case study discussion helped me to understand some of the societal and global issues associated with the practice of engineering technology." The average score of the responses was 4.11, indicating that the students did feel the discussion helped them.

\section{Summary}

Two case studies were developed to provide background for class discussions of ethics and global perspectives in an introductory power and controls course. Student responses on the end of class quizzes and end of semester survey indicated they gained an understanding of these topics. By including the ABET soft-skills directly in technical courses, it is much easier to assess the students achievements of the ABET outcomes for EC 2000 and TC2K.

\section{References}

1. Skvarenina, T.L. \& DeWitt, W. (1998). Development of an EET Electrical Power and Controls Course [CDROM]. 1998 Annual Conference Proceedings, ASEE, six pages.

2. Mead, J. (2002). Ethics in Business: A Summary of the Research Sponsored by the Ethics in Business Research Fund. Charlottesville, VA. Available at http://www.aicpa.org/download/ethics/Ethics_Business_Research_Fund-12.pdf

3. Ethics Resource Center. 2003 National Business Ethics Survey, Executive Summary. http://www.ethics.org/nbes2003/2003nbes summary.html

4. Business Week. Aug 11, 2003. Getting the Lead Out

5. Business Week. October 6, 2003. The Big Picture: Engineering on the Cheap. p. 13 


\section{Biographical Information}

TIM SKVARENINA was born in Chicago, Illinois on December 27, 1947. He received the BSEE and MSEE degrees from the Illinois Institute of Technology and the Ph.D. in electrical engineering from Purdue University. He served 21 years in the U.S. Air Force, including six years designing, constructing, and inspecting electric power distribution projects for a variety of facilities. He spent five years teaching and researching pulsed power systems including railgun systems, high power switches, and magnetocumulative generator modeling. He also has four years experience in operations research, having conducted large scale systems analysis studies for the Strategic Defense Initiative. He has authored or coauthored over 25 papers in the areas of power systems, pulsed power systems, and engineering education. He is the primary author of one textbook and is the Editor-in-Chief of a Power Electronics Handbook.. In the fall of 1991, he joined the faculty of the School of Technology at Purdue University where he primarily teaches undergraduate courses in electrical machines and power systems. He is a senior member of the IEEE; a member of the American Society for Engineering Education (ASEE), Tau Beta Pi, and Eta Kappa Nu; and a registered professional engineer in the state of Colorado. He has served as Chair of the Central Indiana Chapter of the IEEE Power Engineering Society, Chair of the ASEE Energy Conversion \& Conservation Division, Chair of the ASEE Professional Interest Council III, and as Vice President for Professional Interest Councils and member of the board of directors of ASEE. 


\section{Appendix A \\ Case Study: Greenhouse Gases and Global Warming Timothy L. Skvarenina, Purdue University School of Technology}

It is often said that the economies of the world have become a global economy, and many corporations have become multinational in their operations. One might not think of the electric utility industry in the global economy context; however, a number of United States utilities have operations in other parts of the world. One problem that the utilities are a part of, and which has a major global impact, is global warming. This case study will present some of the basics of the issue of global warming and the Kyoto Protocol, which was a treaty designed to reduce the amount of greenhouse gas emissions by the industrialized countries of the world.

\section{Definitions :}

Global

Warming: Increase in the average temperature of the earth beyond the normal year to year variations

Green house

effect: Trapping of heat in the lower atmosphere by clouds and greenhouse gases

Greenhouse

gas: A gas that appears in trace amounts in the atmosphere and causes warming of the lower atmosphere by the absorption of thermal radiation from the earth. The six that are covered by the Kyoto Protocol are: carbon-dioxide $\left(\mathrm{CO}_{2}\right)$, methane $\left(\mathrm{CH}_{4}\right)$, nitrous oxide $\left(\mathrm{NO}_{2}\right)$, hydrofluorocarbons (HFCs), perfluorocarbons (PFCs), and sulfur-hexafluoride $\left(\mathrm{SF}_{6}\right)$

\section{Introduction:}

During the past century, the average global temperature has increased by about $1^{\circ} \mathrm{F}$ according the U.S. Environmental Protection Agency (EPA) and many other scientific or governmental organizations around the world. The 10 warmest years in that timeframe have all occurred since 1983 and seven of them occurred during the 1990s. By examining historical evidence such as tree rings, pollen records, and air locked inside ancient ice, some scientists have concluded that the 20th century was the warmest century, the 1990s the warmest decade, and 1998 the warmest year of the last millennium. These results have led many to conclude that the earth is becoming warmer and that the rate of increase is accelerating.

The earth's atmosphere is composed of $78.1 \%$ nitrogen, $20.9 \%$ oxygen, and $1 \%$ other gases. Over nine-tenths of the $1 \%$ of other gases is argon, leaving less than $0.1 \%$ for a variety of other gases, which occur only in very small, or trace, amounts. Among the trace gases are the greenhouse gases, which serve the important role of trapping heat in the earth's atmosphere, making the planet inhabitable. Without them, the average temperature on the earth would be several degrees below $0^{\circ} \mathrm{F}$. However, as is often the case, too much of a good thing can be bad. 
Increasing the amount of greenhouse gases causes the earth to warm up. While a one degree increase doesn't seem like much, consider that the temperature only decreased by about $9^{\circ} \mathrm{F}$ during the last ice age. An increase of six or seven degrees would cause melting of some glaciers and portions of the polar ice caps resulting in massive flooding of coastal areas. In addition, the entire climate of the world would shift, with heat waves in some places, colder temperatures in others, excessive rainfall in some regions, drought in other. The results of the climatic changes will cause more air pollution, damage to crops, increased disease, and significant loss of human life.

Evidence points to humans as the reason for the increase in the earth's temperature. Since the start of the industrial age, the amount of $\mathrm{CO}_{2}$ in the atmosphere has increased by $30 \%$, from 280 to 367 parts per million by volume. Over 200 billion tons of $\mathrm{CO}_{2}$ are released by the oceans and plant life each year, but a similar amount is absorbed by them as well. Since these actions are balanced, they do not increase the amount of greenhouse gas in the atmosphere. Mankind apparently has upset that balance, however. Carbon dioxide is, of course, a by product of the combustion of carbon-based fuels, including coal, gas, and oil, so the generation of electricity by burning fossil fuels, wood, or biomass creates huge amounts of $\mathrm{CO}_{2}$. Similarly, automobiles and many manufacturing processes contribute additional $\mathrm{CO}_{2}$ to the atmosphere. Methane, which also contributes to the greenhouse effect, is produced by solid-waste landfills and sewage treatment. Nitrous oxide is produced as a result of agricultural processes, such as fertilization of fields. Deforestation for the land development reduces the amount of carbon that can be absorbed from the atmosphere.

All together, human activities are adding some seven billion tons of carbon equivalent to the atmosphere each year. Bear in mind that carbon has an atomic mass of 12 and oxygen 16. Thus, $\mathrm{CO}_{2}$ has a mass of 44 , so the carbon is about $27 \%$ of the weight of the $\mathrm{CO}_{2}$ molecule. Thus, there is about 25.6 billion tons of $\mathrm{CO}_{2}$ being put into the atmosphere each year. About half of the human emissions may be absorbed by the oceans and plants, but the remainder stays in the atmosphere for many years, increasing the greenhouse effect. With the earth's human population approaching 6.5 billion, we are currently emitting a little over a ton of carbon per person per year. Of course, this is an average and the numbers vary dramatically between the industrialized and developing nations. Figure 1 shows the annual per-capita emissions of greenhouse gases in tons of carbon for a number of industrialized countries, as reported by the U.S. EPA. As most would expect, the United States leads the list with 6.6 metric tons ( $1000 \mathrm{~kg}$ or $2200 \mathrm{lbs})$ per person due to the tremendous usage of electricity and gasoline. In fact, the U.S. accounts for approximately $25 \%$ of the world's greenhouse gas emissions. Not shown on the list are the Russian Federation and the developing countries. Russia is second to the U.S., contributing about $15 \%$ of the greenhouse gas emissions. While the developing countries contribute smaller amounts on a per-capita basis, several of them (China, India, Mexico, and Brazil) have rapidly growing economies and are significant emitters of greenhouse gases.

Reducing the rate at which greenhouse gases are added to the atmosphere can be done using a number of methods, such as restricting the amount of emissions or removing them at the source, replacing of fossil fuels by other sources, and reducing deforestation or planting of new forests. 


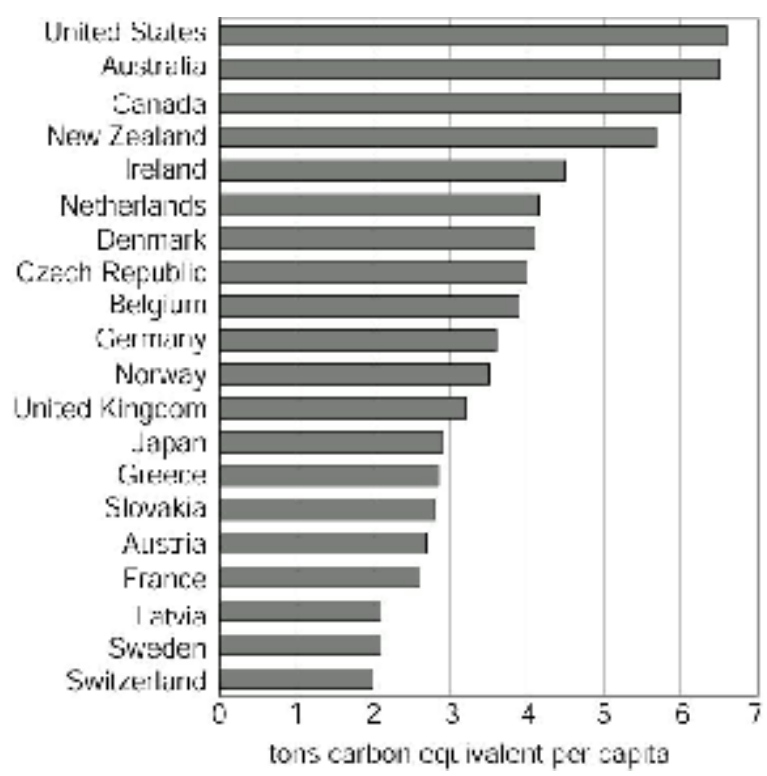

Figure 1: Annual, per-capita greenhouse gas emissions for a number of industrialized nations

\section{World Actions to Address Climate Change}

In 1990 the Intergovernmental Panel on Climate Change (IPCC) issued its first assessment of climate change research, which confirmed that climate change was a threat and calling for a global treaty to address the issue. The United Nations (UN) General Assembly passed a resolution to begin negotiations for such a treaty in December 1990, and in May 1992, the United Nations Framework Convention on Climate Change (UNFCCC) was made available to the nations of the world for signature and ratification. Some 186 nations, including the United States and the European Union, have ratified it and are bound by its provisions. The treaty took effect on March 21,1994. The Convention is a broad framework document that began the process of reducing mankind's impact on the global climate. Specifically, it recognized that there is a problem and that the ultimate objective should be to stabilize the composition of the atmosphere so as to prevent dangerous climatic changes. Finally, it directed that the stabilized level should be achieved in sufficient time to insure the production of food and to allow sustainable economic development.

The Convention was essentially a beginning, because it was not possible to get all the nations to agree to a specific course of action in 1992. Creating the framework allowed discussions of the problem to proceed and created peer pressure throughout the international community. The countries that ratified the Convention agreed to take climatic change into account in a variety of areas and to create programs to slow the rate at which the climate is being changed. Recognizing that the developed countries (Europe, North America, Japan, and others) were largely responsible for the problem, the Convention makes them responsible for cleaning up the problem and paying for it. The developed countries are, for the most part, members of the Organization for Economic Cooperation and Development (OECD).

Forty-one nations including members of the OECD and 14 so-called "economies in transition"

"Proceedings of the 2004 American Society for Engineering Education Annual Conference \& Exposition Copyright 2004, American Society for Engineering Education” 
(countries in Central and Eastern Europe and the former Soviet Union) were listed in Annex I of the convention. The so-called Annex I countries pledged to reduce greenhouse gas emissions so that emissions in the year 2000 would be no higher than they were in 1990. According to the United Nations (UN), they succeeded as a group; however, that was largely due to significant drops ( $>40 \%)$ in the transition countries. Many of the OECD members had increases from 1990 to 2000, including the United States. Figure 2 shows the change in gross domestic product, population, emissions per capita, and emissions per dollar of GDP for the United States from 1990 to 2000. While the per-capita emissions increased only slighty, the population grew by about $14 \%$, resulting in a $16 \%$ increase in the total emissions.

The Convention recognized that developing countries have a right to aspire to better living conditions through economic development, which will require an increase in their share of the global emissions. In 1995 the Intergovernmental Panel on Climate Change (IPCC) issued its second assessment of climate change research and concluded that the process of climate change had probably already started as a result of previous emissions. Pressure was building for additional action that would require specific actions by the developed countries to reduce greenhouse gas emissions. In March 1995, new negotiations were undertaken to define more substantive commitments.

In December 1997, the international community adopted the Kyoto Protocol. According to the UN, "A protocol is an international agreement that stands on its own but is linked to an existing treaty." In this case, the Protocol was linked to the 1992 Convention. Only countries that ratified the Convention could ratify the Protocol; however, countries that chose not to ratify the Protocol would not be bound by it, even though they had ratified the Convention.

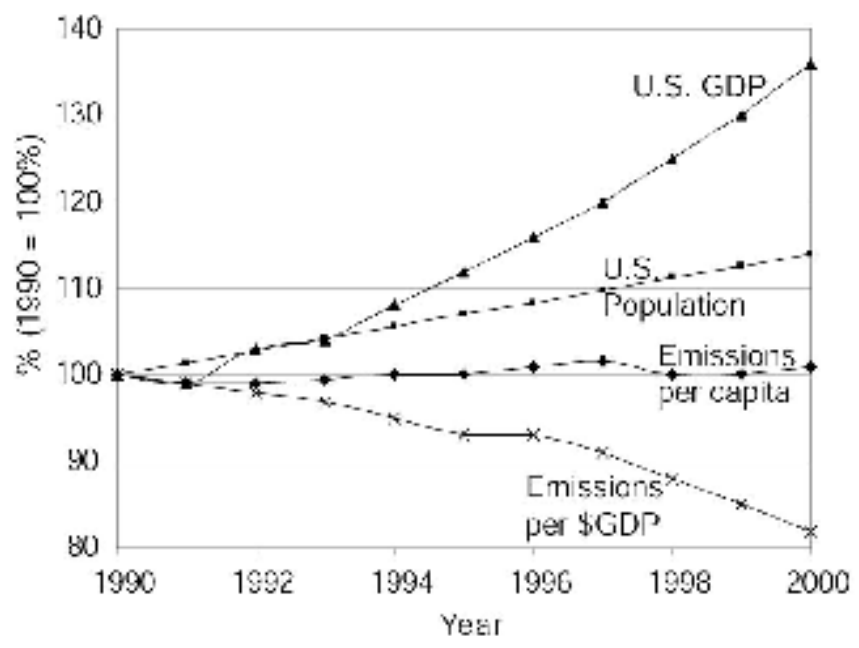

Figure 2: Change of population, per-capita emissions, GDP, and emissions per dollar of GDP from

1990-2000 
The Protocol set legally binding targets for the reduction of emissions in the Annex I countries. Specifically, these countries would reduce their greenhouse gas emissions during the five year period 2008-2012 by 5\% from the levels of 1990 for $\mathrm{CO}_{2}, \mathrm{~N}_{2} \mathrm{O}$, and $\mathrm{CH}_{4}$. For the remaining greenhouse gases (HFCs, PFCs, and $\mathrm{SF}_{6}$ ), the reduction could be from a baseline of 1995, if desired. The reason for the later base year was to compensate for the large increase in the use of these materials as a result of the banning of chlorofluorocarbons (freon) under a 1987 UN Convention. Those materials were banned because they were destroying the ozone layer that protects the earth from UV radiation. Although, the average decrease for greenhouse gas emission was set at 5\%, different requirements were established for each of the Annex I countries. These targets were listed for 38 countries in Annex B of the Protocol and are shown in Table 1. The European Union consists of 15 countries and they allocated their targeted savings in a non-uniform manner among the member countries.

Table 1: $\quad$ Kyoto Protocol required greenhouse gas emission reduction for the Annex I countries

\begin{tabular}{|l|c|}
\hline \multicolumn{1}{|c|}{ Country(ies) } & $\begin{array}{l}\text { Target for change from } \\
\mathbf{1 9 9 0} \text { to 2008-12 }\end{array}$ \\
\hline $\begin{array}{l}\text { European Union, Bulgaria, Czech Republic, Estonia, } \\
\text { Latvia, Liechtenstein, Lithuania, Monaco, Romania, } \\
\text { Slovakia, Slovenia, Switzerland }\end{array}$ & $-8 \%$ \\
\hline United States of America & $-7 \%$ \\
\hline Canada, Hungary, Japan, Poland & $-6 \%$ \\
\hline Croatia & $-5 \%$ \\
\hline New Zealand, Russian Federation, Ukraine & no change \\
\hline Norway & 0.01 \\
\hline Australia & 0.08 \\
\hline Iceland & 0.1 \\
\hline
\end{tabular}

While $\mathrm{CO}_{2}$ is by far the most prevalent of the greenhouse gases, the others can actually have a worse effect for a similar quantity. For example, on a molecule for molecule basis, $\mathrm{SF}_{6}$ has 23,900 times the global warming potential than $\mathrm{CO}_{2}$. Thus, the emissions are converted to carbon equivalent using weighting factors, and the targeted reduction is applied to the entire group of six gases. The Protocol allows a number of ways for a country to meet its reduction. For example, part of the goal could be met by reforestation that creates carbon sinks to remove $\mathrm{CO}_{2}$ from the atmosphere. Other possibilities allow a developed country to pay for a reduction in a developing country and apply the savings to its quota, or for one country to save more than its target and sell credits to another country that is short of its target. The Protocol also allows a country that saves more than is required to "bank" the savings for use in subsequent monitoring periods. Although the average reduction of $5 \%$ sounds small, you should recall from Figure 2, that the United States was already about 16\% over the 1990 
levels by 2000. Considering additional population and GDP growth from 2000 to 2008, the reductions would be well over $20 \%$ from business as usual and would impact many industries

For the Kyoto Protocol to take effect, two things were required. First, 55 nations must ratify the treaty and second, nations that account for at least 55\% of the emissions from the Annex I countries must ratify it. As of May 2003, 109 countries had ratified the document, but that only included 31 Annex I nations that account for about $44 \%$ of the emissions. Thus, the treaty has not gone into effect. The United States and Russia have not ratified the agreement

In the summer of 1997, the United States Senate by a vote of 95-0 passed the Byrd-Hagel resolution, which advised then President Clinton that the Senate would not support any global warming treaty that did not require growing developing economies, such as India, China, Brazil, and Mexico, to participate or that endangered the U.S. economy. Negotiations in Kyoto were seriously bogged down until then Vice President Gore went to Kyoto and instructed the U.S. negotiators to be more flexible. The Protocol was completed in December 1997 and was signed by the United States. However, faced with hostile comments from the Senate, President Clinton never submitted it for ratification, which would have required a two-thirds vote in favor for ratification.

In 2001, several months after taking office, President Bush announced that the U.S. would not ratify the Kyoto Protocol. He indicated that the treaty would cost the U.S. economy millions of jobs and billions of dollars as producers moved to countries that did not have to comply with the Protocol. Instead he proposed that the United States achieve a voluntary $18 \%$ reduction by 2012 in the amount of greenhouse gases emitted per dollar of GDP from a baseline in 2002. In 2002, there were 183 metric tons of $\mathrm{CO}_{2}$ per million dollars of GDP, and under the proposal that would be reduced to 151 metric tons by 2012. Critics of this plan included environmental groups and many European allies, because the total emissions would continue to increase albeit at a slower rate. Some allies, however, applauded President Bush for recognizing that $\mathrm{CO}_{2}$ emissions should be reduced and taking action rather than just ignoring the Protocol.

Faced with withdrawal from the United States, in July 2001 representatives of over 170 nations negotiated a revised version of the Kyoto Protocol that would proceed without U.S. participation, but which also would lower the target reduction from 5\% to 1.8\%. In August 2001, the Foreign Relations Committee of the U.S. Senate unanimously approved (19 to 0) a resolution that asked President Bush to negotiate a global warming treaty that would protect the economic interests of the U.S. and include developing countries. Some executives from large power companies, such as American Electric Power, Cinergy, and Wisconsin Electric Power, have joined in the call for control of $\mathrm{CO}_{2}$ emissions. These individuals have stated their belief that such controls are inevitable and they would rather include them now while they add pollution controls for other gases rather than having to add them later.

A number of individual states have joined in the battle against greenhouse gases by requiring that certain percentages of electricity be obtained from renewable sources by certain dates. Although renewable sources include methane gas from landfills, the largest source of renewable power is wind power. As a result, in 2002 some $410 \mathrm{MW}$ of wind generation was added in the U.S., bringing the total to 4,685 MW in 27 states. California (1822 MW), Texas (1095 MW), and Iowa (423 MW) were the three leading states for wind generation at the end of 2002. With the large increase in wind generation, its cost has become competitive with coal-fired generation. Wind power has also proven

"Proceedings of the 2004 American Society for Engineering Education Annual Conference \& Exposition Copyright 2004, American Society for Engineering Education” 
popular in Europe as a result of the Kyoto Protocol, with a total capacity of about 20,500 MW during 2002. Fifty-percent of that is located in Germany, which added some $2000 \mathrm{MW}$ in 2002 alone, and Denmark derives $18 \%$ of its electricity from wind power. Predictions by the European Wind Energy Association (EWEA) indicate that world wind generation could reach 200,000 MW by 2010.

\section{References}

1. Global Warming and Our Changing Climate, Answers to Frequently Asked Questions. U.S. Environmental Protection Agency, document EPA 430-F-00-011, April 2000

2. A Guide to the Climate Change Convention and Its Kyoto Protocol. United Nations Framework Convention on Climate Change (UNFCCC). Preliminary Version. 2002. Bonn

3. Understanding Climate Change: A Beginner's Guide to the UN Framework Convention and Its Kyoto Protocol. UNFCCC. July, 2002. Bonn.

4. E. Pianin. Emissions Treaty Softens Kyoto Targets. Washington Post. July 29, 2001

5. E. Pianin. Bush Urged to Negotiate Global Warming Treaty. Washington Post. August 2, 2001

7. The U.S. Environmental Protection Agency has information concerning global warming on its website. As this case study was being written, the URL was:

http://yosemite.epa.gov/oar/globalwarming.nsf/content/index.html

\section{Discussion Questions}

1. Assume you are a practicing engineer or technologist. What impact will global warming and the efforts to reverse it have on the decisions you might make in designing products or selecting equipment for a plant? Consider how the requirements of other countries might affect your decisions.

2. What role should the United States play in the efforts to reduce greenhouse gas emissions? Can any nation "go it alone" in the world economy of today?

3. Do you think it is necessary to reduce the standard of living in developed countries to reduce greenhouse gas emissions? What can a country do to combat global warming?

4. Do you, as an individual, believe there is anything you can do to help reduce greenhouse gas emissions? Have we studied anything that can help? 


\section{Appendix B \\ Case Study: Enron \\ Timothy L. Skvarenina, Purdue University School of Technology}

One of the names mentioned frequently during the California crisis was the Enron Corporation, which, at one time, was the largest trader of electricity and natural gas in the world and one of the ten largest companies in the United States. However, Enron came crashing down at the end of 2001 and was forced to file bankruptcy. At the time, it was the largest bankruptcy in the history of the United States. It provides an interesting case study in business ethics.

\section{The Key Players}

Kenneth Lay: $\quad$ He was one of the founders, and first Chief Executive Officer (CEO), of Enron. Chairman at the time of its demise, Lay is a Ph.D. economist who had formerly held several business and government positions. Resigned from Enron in January 2002.

Jeffrey Skilling: Originally an engineering student, he found business more to his liking and received an MBA from Harvard. Employed by McKinsey \& Company, he served as a consultant to Enron prior to joining Enron. He became President and Chief Operating Officer (COO) in May1996 and CEO in February 2001. He resigned in August 2001. Andrew Fastow: $\quad$ As Chief Financial Officer (CFO) of Enron, he was responsible for putting together many "off the books" transactions. He was fired in October 2001.

Michael Kopper: $\quad$ Kopper was an Enron employee who reported to Andrew Fastow.

\section{Enron Background}

The Enron Corporation was formed after a 1985 merger between Houston Natural Gas and Internorth, a gas pipeline company based in Omaha, Nebraska. Thus, Enron began as an interstate natural gas pipeline company. Shortly after the merger, Kenneth Lay became the chairman and Chief Executive Officer (CEO) of Enron. He had a vision for his new company and wanted to take it away from being a pipeline company, remaking it into an energy trading company.

Specifically, with the deregulation of the natural gas business and the proposed deregulation of the electric utilities, price controls would be removed and more companies would be providing energy to the market. However, with a free market, there would also be volatility as prices varied depending upon supply and demand. Here, Lay saw the opportunity for Enron to carve out a business as a trader of energy; i.e., Enron would buy energy from suppliers and contract to sell it at stable prices to customers, while making a profit for itself. A consultant, Jeff Skilling, shared Lay's vision and began helping him implement it by setting up a futures market for gas contracts and by 1989 Enron began trading gas commodities. In 1990, Lay recruited Skilling to join Enron. By 1994, Enron was also trading electricity.

In an interview with the Public Broadcasting System, Jeff Skilling compared the operation of Enron to a bank, with the following explanation. If a large company wants to borrow money they could theoretically go to individuals and borrow the money, but the money in individuals' bank accounts 
varies on a daily basis, depending upon when they get paid and when they pay their bills. So a bank consolidates all the accounts, which tends to smooth out the fluctuations, and loans the money to the large corporation. Enron, according to Skilling, provided a similar service for energy. They contracted with many gas producers and electrical generation companies to buy their output and then sold it to customers at firm prices so the customer could plan on a known cost for energy.

In addition to creating an energy market in the United States, Enron became an international company, building a large power plant in India and water systems in several countries, for example. It also created new trading markets. In 1997, Enron began trading so-called weather derivatives, which essentially insured customers against the results of bad weather, and in 1999 it launched EnronOnline, which as the name implies was a web-based system to trade virtually anything. By 2001, Enron was trading in North and South America, Europe, Asia, and Australia. Among the products traded were Power, natural gas, emission allowances, weather derivatives, coal, oil, steel, shipping, credit (money), and paper. As a result the company income (sales) went from $\$ 13$ billion in 1996 to about $\$ 50$ billion in 1999 and \$101 billion in 2000. Profits, as announced by the company, also continued increasing and Enron became the model for the company of the future, according to a number of published articles. Enron was named as the most innovative company in the U.S. for six years in a row by Fortune magazine.

Enron prided itself as being a "good citizen" and donated significant sums to a variety of charities, universities, museums, and other agencies, although its giving was only average amongst other major companies. Among the donations from Enron were over $\$ 330,000$ with a pledge of $\$ 1.5$ million for a capital campaign to the University of Texas Anderson Cancer Center and $\$ 50,000$ to the George Mason University's Mercatus Center. Enron signed a \$100 million long-term contract to rename the baseball park in Houston as Enron Field. In addition, Enron became highly visible in the political arena, with large contributions to many politicians in both major parties in the United States.

Highly touted by the media, investors bought Enron's stock, causing a rapid run-up in its price, as shown in Figure 1. However, the stock, along with most others, fell from its high point during the latter half of 2000 and early 2001. Unlike, most other companies, though, Enron crashed completely and had to file for bankruptcy in December 2001. The decrease in Enron's stock price from $\$ 90$ to pennies per share, wiped out some $\$ 60$ billion in shareholder equity, much of which was held in retirement accounts and mutual funds. How, could this seemingly huge corporation suddenly collapse? The details are extremely complex and involve a variety of accounting procedures, so the next section will briefly describe the fall of Enron. We will then examine it from the perspective of several key players.

\section{The Fall of Enron}

The first well-known complaints about Enron came from California during its energy crisis. Enron, along with other energy marketeers, was charged with price manipulation by the Governor of California, among others. At the time, Jeff Skilling vehemently denied any market manipulation by Enron; however, later documents showed that Enron engaged in a variety of transactions with names like Deathstar, Fat Boy, Ricochet, and Get Shorty. These transactions were quite complex, but as a simplified example let's consider the Deathstar scheme. Under this action, Enron apparently booked space on power lines from California to Oregon that were controlled by the California ISO, ostensibly

\footnotetext{
"Proceedings of the 2004 American Society for Engineering Education Annual Conference \& Exposition Copyright 2004, American Society for Engineering Education”
} 
to send power to their Oregon subsidiary. However, at the same time, they booked space on a parallel line that was controlled by a California municipal utility to send power in the opposite direction. The result was the transmission lines appeared to be congested, causing the price of delivered power to increase.

While Enron's activities during the California crisis were embarrassing, they did not bring down the company, although they were an example of how the company did business. In 2000, the company reported over $\$ 900$ million in profit, but it turned out that most of it was a mirage. Back in 1992, Jeff Skilling convinced federal regulators to allow a major change in the accounting procedures for Enron. He adopted a method called mark to market, which allowed the company to include earnings that it projected for long term contracts as current income, even though the money might not be collected for 20 years. Following the collapse of Enron, ex-employees asserted that mark to market had been used to inflate reported earnings and to manipulate projections.

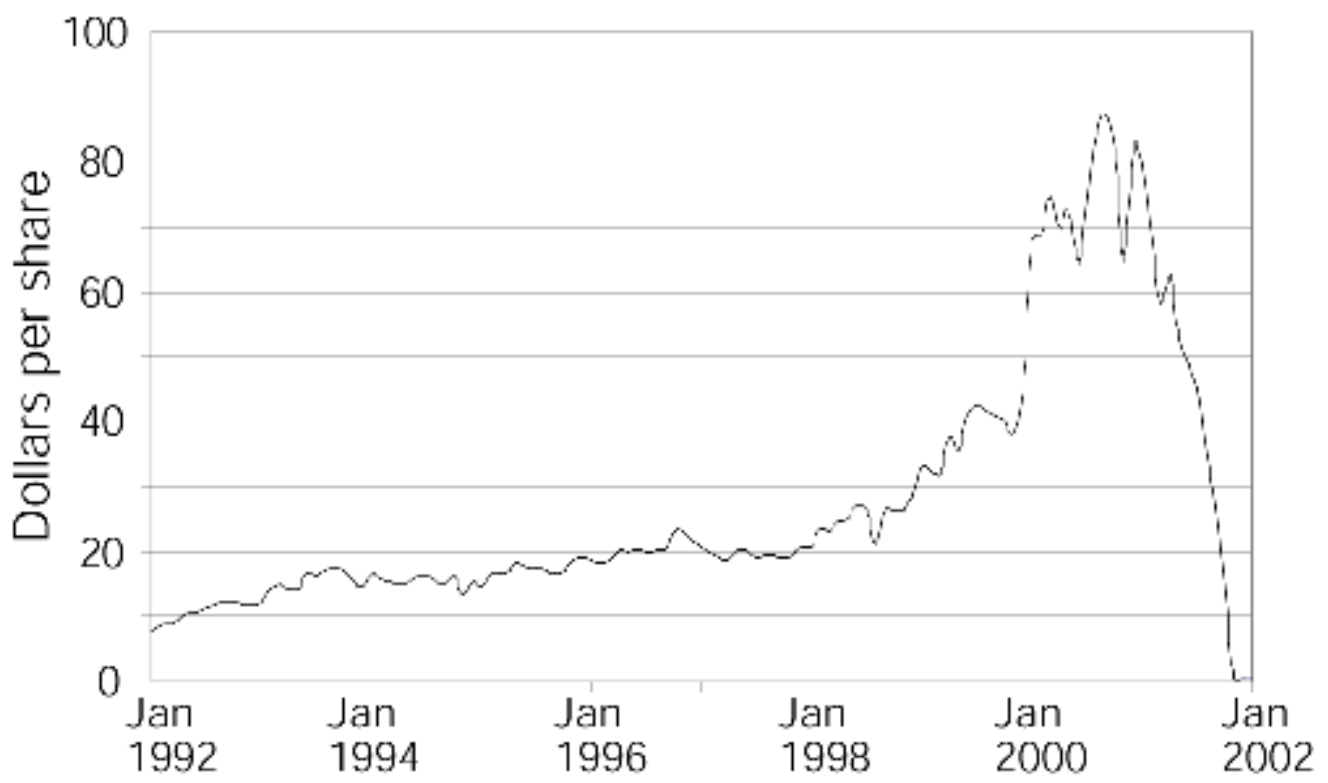

Figure 1: Price of Enron stock from 1992 to 2002

What brought Enron down was its use of very complex, aggressive accounting involving offbalance-sheet transactions and so-called special purpose entities. As a growing company that was creating new markets, Enron found it necessary to acquire assets and then build a market around the assets; for example, power companies, pipelines, and water companies. The problem with acquiring assets was they required money to be purchased, which meant borrowing and if the assets were part of the company, investors expected a return on investment (ROI). Unfortunately for Enron, many of the assets it acquired could not generate sufficient revenue in the short term. Thus, Enron began using a technique known as off-balance-sheet. In this method, Enron would sell an asset to another company, 
which theoretically would be a joint venture between Enron and outside investors. The special purpose entity (SPE) would then borrow money to pay for the asset, but since it was separate from Enron, its debts and assets did not have to appear on Enron's books. This had the effect of reducing the apparent indebtedness of Enron and increasing the ROI. In order for the entity to be treated separately, two major conditions had to be met. First, at least $3 \%$ of the ownership of the SPE had to be independent of Enron and that investment had to be at risk. Second, the independent owner has to have control of the SPE.

Enron used this method successfully for several years, but in 1997 it had some assets to be put into an SPE but there weren't any investors willing to take the risk. As a result, Michael Kopper became the manager and owner of the SPE, known as Chewco (which was short for Chewbacca-Andy Fastow seemed to favor Star Wars movies as Chewco was formed to buy out another partnership called JEDI). However, with insufficient outside capital, Chewco should not have qualified to be treated as a separate company. In 2001, the original decision to treat it separately was reversed and Enron had to reduce its earnings by $\$ 544$ million for the period and reduce its assets by $\$ 1.2$ billion. That action caused investors to want out, rating agencies to reduce the credit rating of Enron. Shortly thereafter, addition SPEs operated by Andy Fastow unraveled and Enron was forced into bankruptcy.

\section{The roles of the key players}

Kenneth Lay was the CEO and Chairman until February 2001, after which he was the Chairman. A Board of Directors investigation found that he did not exercise sufficient oversight of the SPEs that were authorized by the Board through the corporate officers that reported to him. Following the resignation of Jeff Skilling in August 2001, Lay assured the world through an interview in Business Week that there was no bad news to come and that the company was in excellent shape. Lay, as part of his employment, had a revolving credit line of \$7.5 million from Enron. During 2001, he reportedly borrowed from the account on 15 occasions, each time paying the company back with Enron stock that he had held. Had Lay sold the stock in the market, he would have had to report the sale during the following month, but using this technique he wasn't required to report it until February 2002. During the three years prior to the bankruptcy, Lay reported exercising options and selling Enron stock for a profit of \$200 million. Following Skilling's departure, he held an "all hands" meeting with Enron employees and told them that Enron stock was a bargain and that they should be buying it. On October $23^{\text {rd }}$, he held another meeting with employees, promising they would see their Enron shares back at the high values they had seen earlier. But the next day, Lay took a $\$ 4$ million cash advance from the company and \$19 million more over the next three days. He repaid \$6 million using Enron shares, again avoiding the reporting requirement of a stock sale. As Chair, Lay was responsible for bringing items to the Board of Directors for action. In the year prior to bankruptcy, the Board approved bonuses for key personnel totaling $\$ 745$ million, at a time when the company was supposedly making about $\$ 900$ million in profit.

Jeffrey Skilling instituted a very competitive evaluation system at Enron, which provided large rewards to those who could make the big deals that would drive the stock price higher. He was 
responsible for hiring Andy Fastow as the CFO and according to former employees was very much involved in the formation of the SPEs that ultimately bankrupted the company. Specifically, Skilling preached the notion that the company of the future would be composed of intellectual resources not hard assets. He wanted Enron to be an "asset light"company. According to the Board of Directors investigation, Skilling bears significant responsibility for the failure to institute and apply internal controls to control the risk of the SPEs. Skilling reportedly sold stock acquired with options in 2000 that netted some $\$ 62$ million in gains. In August 2001, Skilling told Lay he was leaving the company due to family considerations and on August $14^{\text {th }}$, he and lay announced his departure. Skilling maintained that the company was in strong financial condition and highly profitable when he left.

Andy Fastow was the mastermind behind the scheme to shed assets and debt. Because he was unable to get his bosses to allow him to front the company, he selected Michael Kopper to head up the Chewco Company, which would make Kopper a profit of $\$ 10$ million on a very small investment. Later Fastow would form additional SPEs, called LJM and LJM2 (using the initials of his wife and children) that he himself headed. According to the Board of Directors investigation, Chewco was formed without the Board's knowledge. When LJM and LJM2 were formed, Skilling and Lay presented them to the Board, which approved the SPEs and Fastow's involvement, which involved a waiver of the corporate ethics code. Fastow and six other individuals, all Enron employees or spouses of Enron employees, sought out investors for the LJM partnerships, ranging from Foundations to Teacher Retirement Funds, and eventually made a profit of $\$ 42$ million on a $\$ 161,000$ investment. At the employees meeting on October 23, 2001 Ken Lay expressed complete confidence in Fastow, but Fastow was fired on the $24^{\text {th }}$. Fastow was indicted in October 2002 on 78 counts. In April 2003, he was indicted on another 109 counts; at that time, his wife and seven other former Enron officials were also indicted on a variety of charges.

Michael Kopper was Fastow's top aide. He was the head of the Chewco, Company although his role was never presented to the Enron Board of Directors for approval, and which did not have sufficient outside investors to qualify as a SPE. As a result of his involvement with Chewco, Kopper made a profit of some $\$ 12$ million, and alleges that he made kick back payments to Fastow's family members. In August 2002, Kopper pleaded guilty to charges of money laundering and conspiracy to commit wire fraud. His sentencing was delayed, however, until February 2004, presumably because he was cooperating with authorities investigating other Enron personnel. He also is reported to have promised restitution of the $\$ 12$ million he collected.

\section{The Board of Directors}

The role of a Board is to insure that a company is acting responsibly. Boards are normally composed of inside and independent directors. The Board investigation found that the Board did not sufficiently exercise its oversight responsibilities. The Board approved the formation of the LJM partnership, with Fastow as the head, during a one-hour teleconference that had several other agenda items. After approving Fastow to participate in the LJM partnerships, the Board did not demand sufficient information from the company to determine the effects they had on the company. In its 2001 proxy statement, 14 directors were up for re-election and eight did not have disclosable relationships with

\footnotetext{
"Proceedings of the 2004 American Society for Engineering Education Annual Conference \& Exposition Copyright 2004, American Society for Engineering Education”
} 
Enron. However, several did have financial relationships that might tend to make them less independent.

One member, Wendy Gramm, was the wife of Phil Gramm, U.S. Senator from Texas. Enron had contributed nearly $\$ 100,000$ to Senator Gramm over 12 years, ranking him number 2 in Congress as far as Enron contributions. Ms. Gramm had served as Chair of the Texas Commodity Futures Trading Commission, where in 1993 she helped obtain approval for a regulatory exemption that aided Enron. Five weeks, later, she left the commission and joined the Enron Board. The Directors of Enron were well-paid; Wendy Gramm reportedly earned between \$915,000 and \$1.85 million between 1993 and 2001 in cash and stock. Wendy Gramm headed the George Mason University's Mercatus Center at the time of Enron's collapse. She also served on the Board's Audit and Compliance Committee, which was responsible for overseeing financial operations of the company.

Another member of the Audit and Compliance Committee was John Mendelsohn, president of the University of Texas M.D. Anderson Cancer Center and the chair of the Compensation committee, Charles LeMaistre, is the Cancer Center's president emeritus. The compensation committee had the role of monitoring Fastow's compensation for the LJM partnerships, but in fact never carried out a review. It was not until after he was fired that the board learned of Fastow's and Kopper's financial windfalls. Wendy Gramm pointed out that the company would have to tell the Securities and Exchange Commission (SEC).

\section{The Auditors}

Arthur Andersen served as Enron's auditors from the inception of the company and as such was required to render opinions concerning the setting up of the SPEs and keeping them off the books. Enron was one of Andersen's largest customers, generating some \$50 million in auditing and consulting fees and Andersen had offices in the Enron Building. Andersen, like most major accounting firms, had an oversight committee; however, the local partner in Houston was allowed to overrule suggestions from the oversight committee. Thus, when the appropriateness of the LJM ventures was questioned, the Houston office of Andersen chose to ignore the warning. Later, after Enron was collapsing, a member of the Andersen Headquarters legal staff sent an email to the Houston office reminding them of Andersen's document retention policies and to destroy unneeded documentation. That memo resulted in massive document shredding and deletion of emails at the Houston office and other offices, which eventually resulted in the conviction of the company for obstruction of justice. As a result of the conviction, Andersen essentially ceased to exist as an accounting firm.

\section{The Whistleblower}

Sherron Watkins was a vice-president for corporate development at Enron. The morning after the resignation of Jeff Skilling, Watkins sent an anonymous email to Ken Lay stating, "I am incredibly nervous that we will implode in a wave of accounting scandals." When Lay did not address her concerns at the all-hands meeting, she came forward and arranged a meeting for August 22. During the week between her first email and the meeting she wrote a seven page memo for Lay. Lay met with her and suggested he would have the law firm that the company used extensively look into the matter. Watkins advised against using the same company that had approved most of the deals, but Lay went ahead with them. Watkins had worked at Andersen prior to Enron and knew the people in the

\footnotetext{
"Proceedings of the 2004 American Society for Engineering Education Annual Conference \& Exposition Copyright 2004, American Society for Engineering Education”
} 
Houston office so she sent her concerns to the head Andersen partner assigned to Enron. The partner disseminated her concerns to the Andersen Enron audit team. Her concerns did not become public until January 2002.

In February 2002, while preparing to testify before Congress, Watkins was shown a memo from the law firm to Lay concerning an employee that made a sensitive report. In the memo, the law firm indicated that Texas law did not prohibit the discharge of corporate whistle-blowers. While she was not fired, her boss confiscated her hard drive and her office was moved down 33 floors in the Enron building. Despite her actions, some criticized her for not taking her concerns to the SEC or for selling $\$ 47,000$ of Enron stock after writing her memos.

\section{The Brokers/Investment Bankers}

A key partner in Enron's expansion was the investment banker community, many of which were affiliated with stock brokerages. The bankers raised billions of dollars to invest in the company and the LJM partnerships, while the brokers rated the stock a strong buy nearly to the end of the company. The first sell recommendation was issued on October 24, 2001, the day Fastow was fired. However, in late August 2001, a UBS Paine Webber broker emailed 73 clients and suggested they consider selling their shares. Unfortunately for the broker, some of his clients were Enron executives and the managers of the company's stock option plan demanded that action be taken against broker. Paine Webber was publicly promoting the stock, as well as handling investments for some of the top Enron executives. The broker was fired for giving advice against the company's policy without authorization.

\section{References}

1. W. Powers, R. Troubh, and H. Winokur. Report of the Investigation by the Special Investigative Committee of the Board of Directors of Enron Corp. February 1, 2002

2. Business Week has published numerous articles about the Enron and its collapse, including: Street Wise: Why Enron Isn't Your Run-of-the-Mill Utility, December 6, 2000

Newsmaker Q\&A, Enron's Ken Lay: There's No Other Shoe to Fall, August 24, 2001

The Enron Debacle, November 12, 2001

The Fall of Enron, December 17, 2001

Enron: Let Us Count the Culprits (Editorial), December 17, 2001

Commentary: How Governance Rules Failed at Enron, January 21, 2002

Special Report-The Enron Scandal, January 28, 2002

The Man Behind Enron's Deal Machines, February 4, 2002

Jeff Skilling: Enron's Missing Man, February 11, 2002

At Enron, "The Environment Was Ripe for Abuse," February 15, 2002

News Analysis, Out of Control at Andersen, March 28, 2002

Commentary: No Excuses for Enron's Board, July 29, 2002

News Analysis, Enron: The Prosecution's Game Plan, October 3, 2002

Was Sherron Watkins Really So Selfless? December 16, 2002

What About the Lawyers, December 23, 2002

3. The Washington Post published an extensive analysis of Enron in a five-part series, written by

"Proceedings of the 2004 American Society for Engineering Education Annual Conference \& Exposition Copyright 2004, American Society for Engineering Education” 
April Witt and Peter Behr:

Visionary's Dream Led to Risky Business, July 28, 2002

Dream Job Turns Into a Nightmare, July 29, 2002

Concerns Grow Amid Conflicts, July 30, 2002

Losses, Conflicts Threaten Survival, July 31, 2002

Hidden Debts, Deals Scuttle Last Chance, August 1, 2002

4. N. Benac. Enron and Phil and Wendy Gramm. Associated Press. January 24, 2002

5. K. Eichenwald. Inquiry Now Examining Whether Enron's Assets Were Inflated. New York

Times. December 26, 2002

6. R. McCullough. Congestion Manipulation in ISO California: Testimony Before the Select

Committee to Investigate Price Manipulation of the Wholesale Energy Market. McCullough

Research. June 5, 2002

7. K. Buchler Phillips. Creative accounting and things 'off balance sheet.' Business Money.

September 2002

\section{Discussion Questions}

1. Look up the IEEE Code of Ethics and determine which, if any, of its provisions were violated by the key players.

2. Discuss the actions of Mr. Lay from an ethics standpoint.

3. Discuss the actions of Mr. Skilling from an ethics standpoint.

4. Discuss the actions of Mr. Fastow from an ethics standpoint.

5. Discuss the actions of Mr. Kopper from an ethics standpoint.

6. Discuss the actions of the Board members from an ethics standpoint.

7. Discuss the actions of Arthur Andersen from an ethics standpoint.

8. Discuss the actions of the investment bankers from an ethics standpoint.

9. Should Sherron Watkins have done more than just warn the Chairman of the company that there were problems with the accounting methods?

10. Were the individuals that created trading schemes such as Deathstar acting in an ethical manner? 